\title{
PENERAPAN MODEL PROBLEM BASED LEARNING UNTUK MENINGKATKAN PRESTASI BELAJAR MATEMATIKA
}

\author{
I Wayan Widarsa \\ SMP Negeri 2 Kerambitan \\ e-mail: iwayanwidarsa123@.gmail.com.
}

\begin{abstract}
Abstrak
Penelitian ini dilaksanakan di SMP Negeri 2 Kerambitan Kelas VIII A Semester I Tahun pelajaran 2017/2018 pada mata pelajaran Matematika masing rendah. Tujuan penulisan penelitian tindakan kelas ini adalah untuk mengetahui apakah model pembelajaran Problem Based Learning dapat meningkatkan prestasi belajar Matematika. Metode pengumpulan datanya adalah tes prestasi belajar. Metode analisis datanya adalah deskriptif. Hasil yang diperoleh dari penelitian ini adalah Problem Based Learning dapat meningkatkan prestasi belajar siswa. Ini terbukti dari hasil yang diperoleh pada awalnya mencapai nilai rata-rata 71,37 , pada siklus I mencapai nilai rata-rata 77,37 dan pada siklus II mencapai nilai rata-rata 82,16. Kesimpulan yang diperoleh dari penelitian ini adalah model pembelajaran Problem Based Learning dapat meningkatkan prestasi belajar Matematika Siswa Kelas VIII A Semester I Tahun Pelajaran 2017/2018 SMP Negeri 2 Kerambitan Tabanan.
\end{abstract}

Kata kunci: Prestasi Belajar, Model Pembelajaran Problem Based Learning.

\begin{abstract}
This research was conducted at Kerambitan Middle School 2 Grade VIII A Semester I in the academic year 2017/2018 at the respective Mathematics subjects. The purpose of writing this class action research is to find out whether the Problem Based Learning model can improve Mathematics learning achievement. The data collection method is a learning achievement test. The data analysis method is descriptive. The results obtained from this study are Problem Based Learning can improve student learning achievement. This is evident from the results obtained initially reaching an average value of 71.37, in the first cycle reaching an average value of 77.37 and in the second cycle achieving an average value of 82.16. The conclusion obtained from this study is that the Problem Based Learning model can improve students' Mathematics learning achievement for Class VIII A Semester I Academic Year 2017/2018 of SMP Negeri 2 Kerambitan Tabanan.
\end{abstract}

Keywords : Learning Achievement, Problem Based Learning Model. 


\section{Pendahuluan}

Matematika adalah salah satu mata pelajaran penting yang di pelajari pada semua jenjang pendidikan. Pada tingkat pendidikan dasar dan menengah, matematika dimasukkan dalam kelompok dasar yang harus dikuasai siswa.Penyampaian pembelajaran matematika sangat diperlukan agar siswa dapat memahami dan mengerti mata pelajaran matematika. Guru sebagai pelaku utama proses pembelajaran di kelas merupakan potensi utama perkembangan pendidikan, sudah selayaknya guru setiap saat harus mengembangkan potensinya dalam rangka meningkatkan kualitas pembelajaran.

Seiring dengan berjalannya waktu pendidikan di Indonesia pun banyak mengalami perubahan yang diatur dalam kurikulum pendidikan. Pada Kurikulum 2013 siswa pada proses pembelajaran memiliki tingkat keaktifan dan sikap yang lebih mendominasi daripada domain pengetahuan lainnya. Salah satu pelajaran yang masih diberikan adalah pelajaran Matematika. Matematika merupakan salah satu pelajaran yang ada di SMP.

Salah satu model pembelajaran yang tepat digunakan untuk mengatasi permasalah diatas adalah dengan menerapkan model Pembelajaran Problem Based Learning. Model pembelajaran ini adalah salah satu model pembelajaran bermakna, dimana pada proses pembelajaran selalu berdasarkan atas masalah. Melalui masalah yang ditemuai siswa akan berupaya untuk memecahkan masalah tersebut melalui berbagai cara dan sumber. Apabila siswa sudah menemukan solusi dari setiap masalah yang ditemui maka siswa akan mengamalkannya.

Dari pembahasan di atas maka rumusan masalahnya adalah Apakah penerapan model pembelajaran Problem Based Learning dapat meningkatkan prestasi belajar Matematika Siswa Kelas VIII A Semester I Tahun Pelajaran 2017/2018 SMP Negeri 2 Kerambitan?

Dari rumusan masalah di atas tujuan penelitian ini adalah Untuk mengetahui seberapa tinggi peningkatan prestasi belajar siswa setelah penerapan model pembelajaran Problem Based Learning dalam pembelajaran Matematika Siswa Kelas VIII A Semester I Tahun Pelajaran 2017/2018 SMP Negeri 2 Kerambiatan.

Adapun manfaat teoritis dan praktis dalam pelaksanaan penelitian ini yaitu: secara teoritis, hasil penelitian ini diharapkan akan bermanfaat sebagai acuan dalam memperkaya teori dalam rangka peningkatan kompetensi guru. Sedangkan secara praktis penelitian ini diharapkan bermanfaat bagi sekolah, khususnya SMP Negeri 2 Kerambitan dalam rangka meningkatkan prestasi belajar Matematika. Di samping itu, penelitian ini juga diharapkan bermanfaat sebagai informasi yang berharga bagi teman-teman guru, kepala sekolah di sekolahnya masing-masing.

Model pembelajaran Problem Based Learning adalah model pembelajaran dengan pendekatan pembelajaran siswa pada masalah autentik sehingga siswa dapat menyusun pengetahuannya sendiri, menumbuh kembangkan keterampilan yang lebih tinggi dan inkuiri, memandirikan siswa dan meningkatkan kepercayaan diri sendiri (menurut Arends dalam Abbas, 2000:13).

Model pembelajaran Problem Based Learning merupakan salah satu dari banyak cara yang bisa dilakukan guru dalam upaya meningkatkan mutu pembelajaran. Model ini mempunyai langkah-langkah yang mendorong keaktifan siswa dalam belajar dengan cara memberikan kesempatan bagi siswa untuk lebih banyak mengamati objek atau materi pelajaran, menemukan sendiri hal-hal yang perlu, baik menyangkut materi, meneliti, mengintrogasi, memeriksa materi, sehingga siswa-siswa akan dapat mengalami sendiri 


\section{Metode}

Tempat dilaksanakan penelitian tindakan kelas adalah SMP Negeri 2 Kerambitan. Dengan lokasi yang aman dan lingkungan yang sehat. Banyak pepohonan di sekitar sekolah dan bunga yang bermekaan sehingga lingkungan menjadi indah dan sejuk.

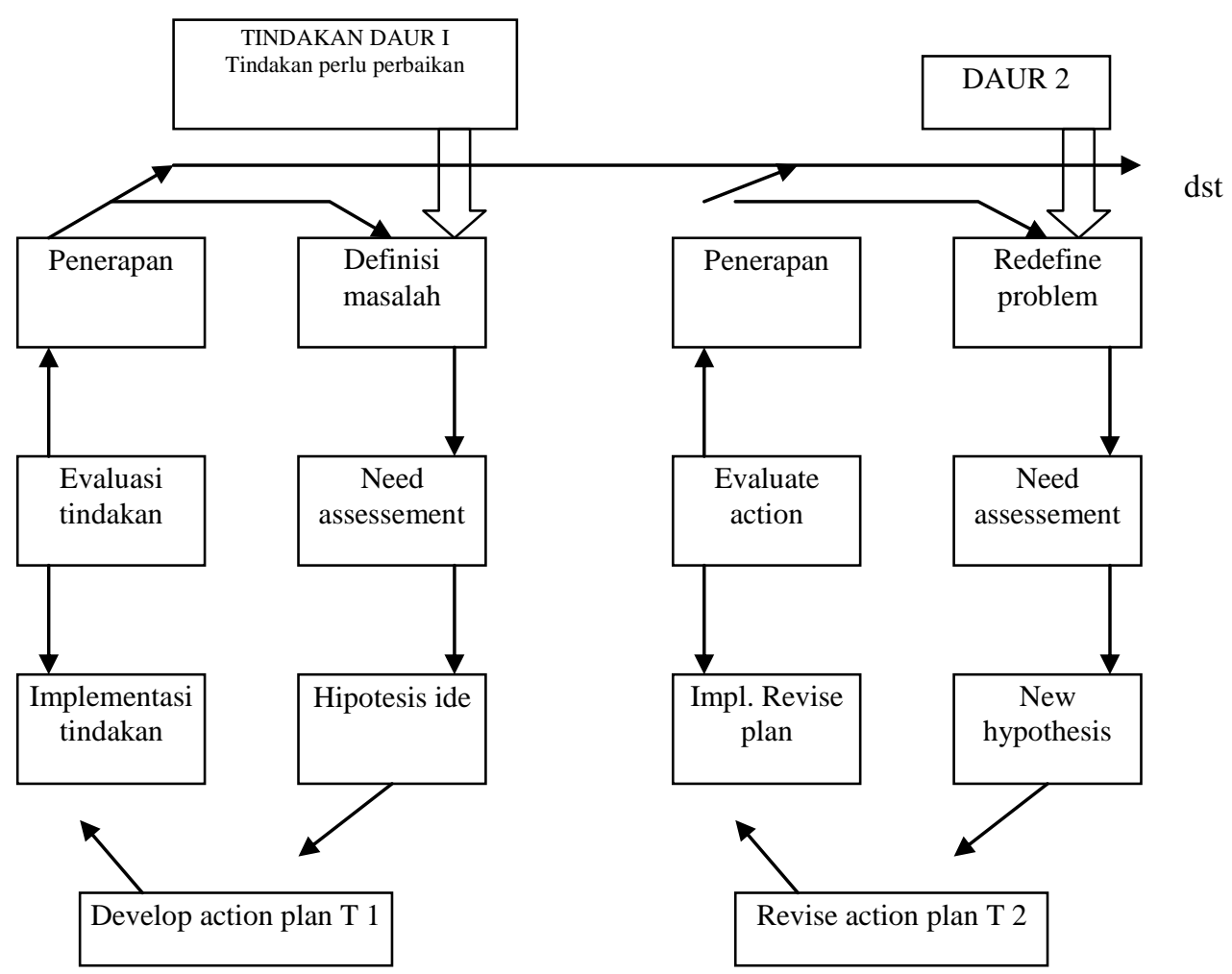

Gambar 1. Penelitian Tindakan Kelas Mc. Kernan, 1991 (dalam Sukidin, Basrowi, Suranto, 2002: 54)

Dalam penelitian ini yang menjadi subjek penelitian adalah siswa kelas IV semester I tahun pelajaran 2017/2018 di SMP Negeri 2 Kerambitan berjumlah 24 orang dengan rincian laki-laki 10 orang dan perempuan 14 orang. Penelitian ini dilakukan di SMP Negeri 2 Kerambitan dari bulan Juli sampai bulan Nopember 2017. Penelitian ini dilaksanakan selama 5 (lima) bulan.

Untuk mengumpulkan data penelitian ini digunakan tes prestasi belajar. Tes dalam penelitian ini digunakan untuk mengukur prestasi belajar Matematika siswa kelas VIII A Semester I Tahun Pelajaran 2017/2018 SMP Negeri 2 Kerambiatan setelah penerapan model pembelajaran Problem Based Learning. Tes dalam penelitian berupa tes tulis yang berupa tes objektif. Tes tersebut berupa butir-butir soal sesuai dengan materi yang telah diajarkan.

Metode yang digunakan untuk menganalisis data hasil penelitian ini adalah metode deskriptif. Untuk data kuantitatif dianalisis dengan mencari mean, median, modus, membuat interval kelas dan melakukan penyajian dalam bentuk tabel dan grafik.

Kriteria keberhasilan pelaksanaan tindakan ini adalah siswa dinyatakan berhasil apabila prestai belajar siswa mencapai sama dengan atau lebih dari nilai 76 sesuai tuntutan KKM yang ditetapkan oleh sekolah dengan persentase hasil belajar siswa secara klasikal sama dengan atau lebih dari $85 \%$ dengan kategori "Baik". 


\section{Hasil dan Pembahasan}

\section{Deskripsi Awal}

Pada bagian ini disampaikan hasil observasi awal: dari 24 orang yang diteliti di kelas VIII A Semester I Tahun Pelajaran 2017/2018 hanya 8 orang atau 34\% mencapai ketuntasan belajar sesuai KKM mata pelajaran Matematika di SMP Negeri 2 Kerambiatan.

\section{Deskripsi Siklus I}

a. Rencana Tindakan I

Hasil yang didapat dari kegiatan perencanaan meliputi:

- Menyusun RPP mengikuti alur model pembelajaran Problem Based Learning

- Menyiapkan bahan-bahan pendukung pembelajaran seperti media pembelajaran, alat evaluasi, materi pembelajaran dan buku paket.

b. Pelaksanaan Tindakan I

- Kegiatan pendahuluan (siswa difasilitasi gambar tentang topik materi)

- Kegiatan inti (siswa ditugaskan mengerjakan LKS secara berdiskusi dengan anggota kelompok heterogen dan dilanjutkan mempresentasikan hasil diskusi)

- Kegiatan penutup (menyimpulkan, evaluasi, refleksi, dan pemberian PR)

c. Observasi

Hasil yang diperoleh dari tes prestasi belajar dapat dijelaskan antara lain: dari data jumlah siswa sebanyak 26 (74\%) orang sudah mencapai KKM, sedangkan 9 orang (26\%) yang memperoleh nilai di bawah KKM,

a) Refleksi

analisis kuantitatifnya mengingat data yang diperoleh adalah:

1. Rata-rata (mean) dihitung dengan: $\frac{\text { Jumlah nilai }}{\text { Jumlah siswa }}=\frac{1857}{24}=77,37$

2. Median adalah: 80

3. Modus adalah: 80

4. Untuk persiapan penyajian dalam bentuk grafik maka hal-hal berikut dihitung terlebih dahulu.

1) Banyak kelas $(K)=1+3,3 \times \log (N)$

$$
\begin{aligned}
& =1+3,3 \times \log 24 \\
& =1+3,3 \times 1,38 \\
& =1+4,5=5,5=6
\end{aligned}
$$

2) Rentang kelas $(r)=$ skor maksimum - skor minimum

$$
=90-61=29
$$

3) Panjang kelas interval (i) $=\frac{r}{K}=5$

Tabel 1. Data Kelas Interval Siklus I.

\begin{tabular}{clrcc}
\hline No & Interval & Nilai Tengah & Frekuensi Absolut & Frekuensi Relatif \\
\hline 1 & $61-65$ & 63 & 2 & $8 \%$ \\
2 & $66-70$ & 68 & 2 & $8 \%$ \\
3 & $71-75$ & 73 & 5 & $21 \%$ \\
4 & $76-80$ & 78 & 8 & $33 \%$ \\
5 & $81-85$ & 83 & 4 & $18 \%$ \\
6 & $86-90$ & 88 & 3 & $12 \%$ \\
\hline TOTAL & & 24 & $100 \%$ \\
\hline
\end{tabular}




\section{Deskripsi Siklus II}

a. Rencana Siklus II

Hasil yang didapat dari kegiatan perencanaan meliputi:

- Menyusun RPP mengikuti alur model pmbelajaran Problem Based Learning

- Menyiapkan bahan-bahan pendukung pembelajaran seperti media pembelajaran, alat evaluasi, materi pembelajaran dan buku paket.

b. Pelaksanaan Tindakan I

- Kegiatan pendahuluan (siswa difasilitasi gambar tentang topik materi)

- Kegiatan inti (siswa ditugaskan mengerjakan LKS secara berdiskusi dengan anggota kelompok heterogen dan dilanjutkan mempresentasikan hasil diskusi)

- Kegiatan penutup (menyimpulkan, evaluasi, refleksi, dan pemberian PR)

c. Pengamatan/Observasi II

Hasil yang diperoleh dari tes prestasi belajar dapat dijelaskan sebagai berikut: dari 24 orang sudah 22 siswa 92\% kelas VIII A SMP Negeri 2 Kerambiatan sudah mencapai ketuntasan KKM. Sedangkan 3 orang siswa $(8 \%)$ mendapat nilai di bawah KKM. Sehingga dari hasil penelitian tersebut dapat disimpulkan bahwa penerapan model pembelajaran Problem Based Learning sudah mencapai indikator keberhasilan dan penelitian pada siklus II tidak melanjutkan kesiklus berikutnya dan dihentikan pada siklus II.

d. Refleksi II

Analisis kuantitatif disampaikan sebagai berikut :

1. Rata-rata (mean) dihitung dengan: $\frac{\text { Jumlah nillai }}{\text { Jumlah siswa }}=\frac{1964}{24}=81,83$

2. Median adalah: 80

3. Modus adalah: 80

4. Untuk persiapan penyajian dalam bentuk grafik maka hal-hal berikut dihitung terlebih dahulu.
1) Banyak kelas $(K)=1+3,3 \times \log (N)$

$$
\begin{aligned}
& =1+3,3 \times \log 24 \\
& =1+3,3 \times 1,38 \\
& =1+4,5=5,5=6
\end{aligned}
$$

2) Rentang kelas $(r)=$ skor maksimum - skor minimum

$=90-61=29$
3) Panjang kelas interval (i) $=\frac{r}{K}=5$

Tabel 2. Data Kelas Interval Siklus I

\begin{tabular}{clccc}
\hline No & Interval & Nilai Tengah & Frekuensi Absolut & Frekuensi Relatif \\
\hline 1 & $61-65$ & 63 & 1 & $4 \%$ \\
2 & $66-70$ & 68 & 1 & $4 \%$ \\
3 & $71-75$ & 73 & 1 & $4 \%$ \\
4 & $76-80$ & 78 & 7 & $29 \%$ \\
5 & $81-85$ & 83 & 9 & $38 \%$ \\
6 & $86-90$ & 88 & 5 & $21 \%$ \\
\hline TOTAL & & 24 & $100 \%$ \\
\hline
\end{tabular}

Data yang diperoleh dari hasil pelaksanaan tindakan siklus I sampai dengan siklus II adalah dimulai dari data awal yang diperoleh dengan rata-rata 71,37 menunjukkan bahwa kemampuan siswa dalam mata pelajaran Matematika masih sangat rendah mengingat kriteria ketuntasan belajar siswa untuk mata pelajaran ini di SMP Negeri 2 Kerambitan adalah 76. Dengan nilai yang sangat rendah seperti itu maka peneliti mengupayakan untuk dapat meningkatkan prestasi belajar siswa menggunakan model pembelajaran Problem Based Learning. Akhirnya dengan penerapan model pembelajaran Problem Based Learning 
yang benar sesuai teori yang ada, peningkatan rata-rata prestasi belajar siswa pada siklus I dapat diupayakan dan mencapai rata-rata 71,63. Namun rata-rata tersebut belum maksimal karena hanya 25 siswa memperoleh nilai di atas KKM sedangkan yang lainnya belum mencapai KKM. Sedangkan prosentase ketuntasan belajar mereka baru mencapai $72 \%$. Hal tersebut terjadi akibat penggunaan pembelajaran Problem Based Learning belum maksimal dapat dilakukan disebabkan penerapan model tersebut baru dicobakan sehingga guru masih belum mampu melaksanakannya sesua alur teori yang benar.

Pada siklus ke II perbaikan prestasi belajar siswa diupayakan lebih maksimal dengan peneliti membuat perencanaan yang lebih baik, menggunakan alur dan teori dari model pembelajaran Problem Based Learning dengan benar dan lebih maksimal.Peneliti giat memotivasi siswa agar giat belajar, memberi arahan-arahan, menuntun mereka untuk mampu menguasai materi pelajaran pada mata pelajaran bahasa Indonesia lebih optimal. Akhirnya dengan semua upaya tersebut peneliti mampu meningkatkan prestasi belajar siswa pada siklus II menjadi rata-rata 81,83 dengan prosentase ketuntasan belajar mencapai $92 \%$. Upaya-upaya yang maksimal tersebut menuntun kepada penelitian bahwa model pembelajaran Problem Based Learning mampu meningkatkan prestasi belajar siswa.

\section{Simpulan dan Saran}

\section{Simpulan}

Berdasarkan pemaparan hasil penelitian, maka kesimpulan yang dapat ditarik adalah: Dari data awal ada 16 siswa mendapat nilai dibawah KKM dan pada siklus I menurun menjadi 9 siswa dan siklus II ada 3 siswa mendapat nilai di bawah KKM. Dari rata-rata awal 71,37 naik menjadi 77,37 pada siklus I dan pada siklus II naik menjadi 81,83. Dari data awal siswa yang tuntas hanya 8 orang sedangkan pada siklus I menjadi lebih banyak yaitu 15 siswa dan pada siklus II menjadi cukup banyak yaitu 22 siswa. Atas bukti-bukti pencapaian tujuan pembelajaran sehingga dapat disampaikan bahwa implementasi model pembelajaran Problem Based Learning dapat meningkatkan prestasi belajar Matematika Siswa Kelas VIII A Semester I Tahun Pelajaran 2017/2018 SMP Negeri 2 Kerambiatan.

\section{Saran}

Dapat disampaikan saran-saran sebagai berikut: Dalam melaksanakan proses pembelajaran pada mata pelajaran Matematika, penggunaan model pembelajaran Problem Based Learning semestinya menjadi pilihan dari beberapa metode yang ada mengingat metode ini telah terbukti dapat meningkatkan kerjasama, berkreasi, bertindak aktif, bertukar informasi, mengeluarkan pendapat, bertanya, berdiskusi, berargumentasi dan lain-lain. Selanjutnya untuk adanya penguatan-penguatan, diharapkan bagi peneliti lain untuk melakukan penelitian lanjutan guna verifikasi data hasil penelitian.

\section{Daftar Pustaka}

Abdullah. 2002. "Fungsi Prestasi belajar Siswa" http://www.scribd.com/doc/9037208/. (diakses tanggal 20 Oktober 2014).

Agung, A.A. Gede. 2005. Metodologi Penelitian Pendidikan Suatu Pengantar. Singaraja: FIP IKIP Negeri Singaraja.

2010. Pengantar Evaluasi Pendidikan. Singaraja: Jurusan Teknologi Pendidikan Fakultas IImu Pendidikan Universitas Pendidikan Ganesha.

Arikunto, Suharsimi; Suhardjono; Supardi. 2006. Penelitian Tindakan Kelas. Jakarta: PT Bumi Aksara.

Badan Standar Nasional Pendidikan.2007. Peraturan Menteri Pendidikan Nasional Republik Indonesia Nomor 41 Tahun 2007.Jakarta: BSNP. 